\title{
The Sense-organs and Perceptions of Fishes; with Remarks on the Supply of Bait.
}

\author{
By
}

W. Bateson, M.A.,

Fellow of St. John's College, Cambridge, and Balfour Student in the University.

With Plate XX.

The Council of the Marine Biological Association appointed me, in 1889 ,* to make observations on the perceptions of fishes, and espe cially on those which constitute the modes by which they hunt for and recognise their food. It was suggested that this subject should be treated in as wide a manner as possible, and in accordance with this suggestion I have endeavoured to utilize any opportunities which presented themselves of getting an insight into the natural history of marine animals. In addition to this I have also made some experiments towards the practical solution of the bait question, both by making artificial baits, and by endeavouring to preserve materials which are already in use for bait.

The first part of this paper contains an account of those observations which seem to have a scientific interest; and it is followed by some remarks on the present condition of the supply of bait, together with suggestions as to possible solutions of the difficulty.

Evidence bearing on the perceptions of aquatic animals is somewhat difficult to obtain, owing to the absence of any points of similarity between the conditions of their lives and those of terestrial forms. To interpret their behaviour by comparison with our own is even more clearly an inadequate treatment than it is in the case of the other lower animals. From the nature of the case, moreover, satisfactory evidence as to their conduct in the wild state is scarcely to be had, so that it is necessary to depend largely upon observations made upon them while living in tanks. It must be understood, therefore, that the statements here made are, strictly speaking, descrip-

* This appointment was made in connection with Mr. Robert Bayly's grant to the Association for an investigation of the means whereby deep-sea fishermen may be better supplied with bait. 
tive only of their habits under these artificial conditions. Though the majority of the fishes observed by me, being inhabitants of water of moderate depth, may be assumed to be under approximately natural conditions, it is important to bear this reservation in mind in considering the case of conger and other fishes which live in deeper water, and are exposed in the sea to very different influences, especially as regards pressure and light. As an instance of the need for caution in estimating the powers of fishes by their behaviour in tanks, it may be mentioned that the whiting, though a diurnal feeder, and apparently unable to find its food otherwise than by sight, is nevertheless under exceptional circumstances caught in the sea with a bait on dark nights at a considerable depth.

It will perhaps be convenient to give a general account of the sense-organs of the animals before describing their habits and modes of perception.

\section{The Structure of the Sense-organs.}

In examining the sense-organs of fishes I have been a good deal struck with a general fact concerning them, which, though sufficiently well known and obvious when stated, does not appear to be a matter of a priori necessity, and it may be well to call attention to it in this place. On comparing individual fishes of the same species but of different sizes, it is apparent that the size of the eyes varies with the size of the body. The same fact is true of the scales covering the body, which seem not to increase in number, but in size as the animal grows. In fact, so constant is the number of the scales that, as is well known, they have value as characters for the purposes of classification. In the case of the olfactory organs, increase in size takes place both by growth of the individual folds bearing the epithelium, and by the addition of new folds. Now the relation of such an organ as the eye to the organism may be compared to that of an instrument to a workman; and if this comparison is a true one, it is not a little remarkable that the sizes of the two should vary together. The question next arises, is a large eye, cæteris paribus, more efficient than a small one? It may easily be - believed that a larger olfactory organ is more efficient, but such a case as that of the eye seems more difficult. If this question should be answered in the negative, it would be interesting to see if these facts are in harmony with the principle of economy of growth, in obedience to which it is believed that all superfluous parts tend to be eliminated from the body. If it is held by any to be manifest that a larger organ is obviously more efficient by reason of its greater 
size, it may be asked to what limit it is proposed to carry this principle. Is it applicable to all organs and parts of organs? Are the cells, for instance, of the tissues of a large individual larger than the similar cells in a smaller one, or would they be more efficient if they were? It would in any case be most desirable to know in what animals this relation of size between the whole and the parts is found, and to what organs it extends. In particular, it would be of the highest interest to know whether the eggs of a large individual are larger or more numerous than those of a smaller individual of the same species, and so on. An insufficient experience of Crustacea, fishes, and plants leads one to think that in these cases the number of eggs or seeds increases without change of size, though in the absence of more data it is unprofitable to discuss the matter. But as the relation between the size of the body and that of its organs has a high importance in any attempt to obtain a view of the modes of occurrence of variations, these facts in the structure of fishes are emphasized here, in the hope that persons who have the opportunity of handling large numbers of animals may be led to record their observations of similar particulars.

\section{Eyes.}

The general structure of the eyes of fishes is well known, but some points which have been observed in the course of this investigation may be worthy of notice. Particular attention was paid to the eyes of those fishes which are active at night, in order to see if there is any general common feature among them. The statement, for example, is made by Day (British Fishes, vol. i, p. xxviii) that " nocturnal fishes require larger eyes than diurnal ones." This may possibly be true, but it is by no means the fact that they are as a rule endowed with larger eyes, as is suggested in the passage quoted. The most typically nocturnal fishes are the conger and the eel. Of these the conger has a large eye, but not a remarkably large one when compared with that of the cod or the bream, which are diurnal, while the eel has a somewhat small eye. The eyes also of the sole, which is emphatically a nocturnal animal, are singularly small, while those of the angel-fish and torpedo are still smaller in proportion to the bulk. Among the rocklings, also night-feeders, the three-bearded rockling has an eye of average size, while that of the five-bearded rockling is decidedly small in proportion to its body. Under these circumstances any general statement is misleading.

Not even is there any uniformity with regard to the presence or 
absence of a contractile iris amongst nocturnal or diurnal fishes. In this Journal (N. S., i, 2, p. 215) I have given some account of my experience in this matter, which it may be convenient to repeat here, with the addition of other facts since noticed.

In the great majority of fishes observed, the shape and size of the pupil do not alter materially for light. Of the exceptions in which such a mechanism is found, some are nocturnal, as the skate and rough dog-fish, while others are diurnal animals, as the turbot. All of the Elasmobranchs which came under my notice are provided with a contractile iris, but the mode of contraction and the form of the pupil differ greatly among them. The eye of the torpedo (T. marmorata) presents the simplest form of this mechanism. In it the pupil is circular by night, but by day the lower limb of the iris rises up so as to close the pupil almost completely, leaving a horizontal slit at the upper part of the eye ( $v$. fig. 8$)$. In the rough dog-fish, the angel-fish, and the nursehound the pupil is also closed by day, but in it the edges of the iris meet to form an oblique slit passing across from the upper posterior margin of the iris to the lower anterior one. The arrangement in the skate is altogether peculiar, and seems to have no relation to either of these types of mechanism. In it the pupil is covered in daylight by a process of the upper limb of the iris, which falls over it, forming the wellknown fern-shaped structure ( $v$. figs. $7 a$ and $7 b$ ). This peculiar irideal fold seems to consist of a constant number (eleven) of processes. By night this fold is completely drawn up, leaving the pupil clear. As described in the place referred to, the pupils of the dogfish and skate contract at night when the light of a lantern is turned on the eye, but this contraction is not sudden, as it is in terrestrial animals and Cephalopods, but, on the contrary, takes a long time to be completed. In the skate the process of the iris did not completely descend when the eye had been exposed to light for about twenty minutes, but the pupil of the dog-fish wąs almost entirely closed in that time. Illumination of one eye only in the skate causes the irideal fold of both sides to descend simultaneously, but the pupil of the dog-fish remained open on the dark side when the folds of the iris had nearly met in the illuminated eye.

The eye of the sterlet (Acipenser), a night-feeder, also has a contractile iris, which is arranged as a circle which is incomplete at the upper edge ( $v$. fig. 10).

Among diurnal fishes, the turbot and brill, together with the weever, all have a semicircular flap from the upper edge of the iris which partially covers the pupil by day, but is almost entirely retracted at night, slowly returning under the light of a lantern. In the Brighton Aquarium I saw a turbot in which this flap of the 
iris was hardly developed at all. In speaking of the weever as a diurnal fish it is not intended to assert that it is not active at night. As is well known, it lives buried in the sand by day, but it has eyes which see well in daylight, for it will uncover itself and swim up to food just as a plaice does. As to its habits at night I have no evidence.

The pupil of the halibut is kidney-shaped, the concavity being upwards. The pupil of the plaice is of the same pattern, and without special irideal mechanism.

The pupil of the gurnard differs from all these in being slightly contracted by day so as to have a diamond shape, while it is circular by night.

All the fishes attainable were tested with a lantern by night, but in none was any alteration in the size of the pupil observed except in the cases mentioned. It is a somewhat remarkable fact that the reflex contractility of the iris, which is such a general character of land Vertebrata, should be so irregularly developed among fishes. In none of them does the usual sudden contraction for light occur, though it is nevertheless found in the Cephalopods (v. loc. cit.). Moreover, as the matter may have a bearing on the optical aspects of aquatic vision, attention is called to the fact that none of the animals mentioned which are provided with appliances for contracting the pupil have the circular aperture which is usual in many terrestrial animals and also in several of the other fishes which have no special mechanism of this kind.

The eyes of the three-bearded rockling (night-feeder) are extraordinarily convex, and protrude from the general level of the face so much that the lens can be seen through the cornea on looking down on the animal's head from the dorsal side. The same is true of the eyes of the boar-fish (Capros aper), which is a day-feeder; while those of the conger, also a night-feeder, are particularly flat.

The eyes of fishes are mostly not capable of much rotation, but those of the dory, wrasses, lump-sucker, and pipe-fishes can all be moved, and are used independently of each other (cf. p. 242). The eyes of the loach are also moveable, but to a less extent.

\section{Olfactory Organs.}

In all the fishes examined olfactory organs are present, but their development differs greatly in the different forms, the largest occurring in the eel, the conger, the Raiidæ, and the dog-fish, and the smallest in the top-knot (Zeugopterus punctatus). It might be expected that the olfactory organs of fishes which hunt by scent 
would be consistently larger than in those which seek food by sight, but this is only partially true. For though the great development of these parts in the eel, conger, and Elasmobranchs is accompanied by an acute sense of smell, yet in the rocklings, the loach, and the sole, which also seek their food by scent, the olfactory organs cannot be said to be proportionally more developed than they are in forms which feed by sight, such as the plaice and the pollack.

Nostrils.-In all forms (? Zeugopterus punctatus) examined, two nostrils occur on each side in the manner characteristic of most fishes. Of these two nostrils the anterior is to some extent tubular in all the fishes (except the Elasmobranchs) which seek their food by scent (v. p. 235). This tube is most developed in the conger, in which it is simple and straight, projecting beyond the surface of the nose. In the eel this anterior portion of the nostril is formed of two flaps of skin. In the rocklings it takes the form of a very short tube, the dorsal edge of which is produced into a long barbel. The anterior nostril of the loaches resembles that of the rockling, but the tube stands up more vertically from the head, and the posterior edge of the aperture is not produced into a barbel, but is bent over it to form a kind of hood. This latter form of nostril is also found in nearly the same shape in Lepadogaster. In all these forms the posterior nostril is a simple opening without a valve.

These tubular nostrils are ciliated as well as the olfactory epithelium itself, and a current is thus caused which enters by the anterior and leaves by the posterior opening. In the majority of fishes rhythmical oscillations of the water in the olfactory pits also occur, but these are not present in any of the animals mentioned below as seeking food by scent, except Lepadogaster.

In the ordinary round fishes (Gadidx, Labridx, \&c.) the two nostrils are placed close together. Through these openings currents are no doubt caused by the cilia on the olfactory organs themselves, but the principal movement of water in the olfactory chambers is an oscillatory movement which occurs rhythmically, keeping time with and being probably dependent on the respiratory movements of the fish. The former movements may nevertheless be suspended while the respiratory movements continue. It did not appear that in these fishes the water entered or left by either nostril in particular, but rather that it oscillated in and out through both of them at once.

In the flat-fishes the arrangement of this current is more complicated. The plaice may be described as having the structure which is found in most of them. This fish lies on its left side. The anterior nostrils are tubular, that of the right side being produced con- 
siderably. The posterior nostril of the right side is valvular, and opens outwards. On inspiration water passes into the olfactory chamber through the anterior nostril, and on expiration the posterior nostril opens suddenly as the water passes out through it. The posterior nostril of the left side is not valvular, but simple. These remarks apply also to the dab and the flounder. In all these fishes the nostrils are so arranged that none of them are on the lower surface of the head, but rather on its dorsal side.

The sole has a different mechanism. It lies on its left side, and both the nostrils of the left side are on the under surface of the head - touching the ground, in fact, when the animal is at rest. On the left side the anterior nostril is large and open, and has a ciliated fold of skin which passes spirally down it; but the posterior one is very inconspicuous and valvular, being at some distance from the anterior opening. As the sole inspires, water passes in at the anterior opening, and on expiration it leaves by the posterior nostril, which opens and shuts with a jerk. The anterior nostril of the right side is tubular, and the posterior one is valved, acting like that of the left side.

In all these fishes, also, the flow of water through the olfactory organs may be suspended though the respiratory movements continue.

In the turbot, which lies on its right side, the left anterior nostril is guarded by a simple triangular flap of skin which projects forward from the posterior edge of the opening and covers it. This possibly forms a valve during life, though I have not had an opportunity of closely examining the currents through the olfactory chamber in a living specimen. The posterior edge of the anterior nostril on the left side is produced into a very large, leaf-like flap of skin, which in dead specimens usually covers the nostril. In one specimen (from Grimsby), however, this fold was reflexed, and lay against the side of the head in such a rigid manner that it could not have been used during life to cover the nostril.

The right posterior nostril of the turbot is widely open, and the left posterior nostril is also without any special valve, but the skin at its edges nearly meets across the opening. These structures do not materially differ in the brill ( $R$. levis). In one brill (from Grimsby) the two nostrils of the right side were united, forming a common fossa in which the olfactory organ lay. In this specimen the leaf-like fold of skin, usually covering the anterior nostril, was divided into two parts, which were disposed on either side of this fossa. There was no indication that this variation was not congenital.

The left anterior nostril of Arnoglossus laterna is somewhat tubular, but the left nostrils of Arnoglossus megastoma, which also lies on its right side, were, in a preserved specimen, without valves or flaps of 
skin of any kind. The right anterior nostril, however, has a very large loose flap of skin. The olfactory folds are but slightly developed, and are mere ridges on the floor of the olfactory chamber. Their number in the left organ of a large specimen was thirty ( $v$. fig. 3).

The olfactory structures of Müller's top-knot (Zeugopterus punctatus) are so abnormal and reduced that it will be best to reserve any statement about them until the homologies of the parts are more clear.

The olfactory organs themselves in fishes are composed of the wellknown folds bearing the sensory and supporting cells of the epithelium. On this occasion I propose to give an account of the general structure of these organs, deferring the description of the histology until a full comparison can be made between the olfactory elements of the fishes which hunt by scent with the same parts in those which seem not to use their olfactory organs for this purpose.

The arrangement of the olfactory folds differs in the various fishes. Roughly speaking, they are built up on one of four types, or on some plan intermediate between them.

(1) In the skate and dog-fish the plates are arranged in a radiating manner on the inside of a hollow capsule, like the septa of an orange. In this case the free internal edges of the plates do not bear sensory cells, but are fibrous supporting tissues.

(2) The conger and eel have the plates of the organ arranged in two rows on each side of a central raphe, upon which the two rows are folded longitudinally so as to form the lining of the olfactory tube. The olfactory organ of the sole, though a much less considerable structure, is arranged on a similar plan; for on it the longitudinal raphe is depressed so as to form a groove from which the plates rise up on each side. The number of plates in an eel one and a half feet long was about thirty-eight pairs in each organ. As already mentioned, the number and size of these plates increase with the growth of the animal.

(3) The third type of olfactory organ, of which the second is a modification, is that most commonly found among fishes. In it the plates are fitted together in a radiating manner, forming a convex eminence in the olfactory chamber. The whole organ is either circular (as in Cottus and Motella mustela) or elliptical (as in the mackerel), according to the number and shape of the plates of which it is composed.

In all the Teleosteans hitherto mentioned most of the plates are placed at right angles to the long axis of the body, and each organ essentially consists of two rows of such plates united in the middle; for the circular collection of radiating plates of Cottus, \&c., only differs in degree from the more common elliptical one. 
Amongst the flat-fishes this elliptical series of plates arranged along a single axis is found in the genera Rhombus (turbot and brill) and Amoglossus (merry sole and megrim). In a very large turbot the number of chief folds was thirty.

(4) In all the species of Pleuronectes* examined, as well as in Hippoglossus vulgaris (the halibut), an entirely different arrangement is found. In these fishes ( $v$. fig. 2 ) only one row of olfactory plates is present. The plates thus arranged in a single series lie in a direction parallel to the long axis of the body, and not transversely to it, as the majority of them do in other types. The arrangement in Solea has already been described.

In the pollack and rockling, and probably in all fishes, if the whole olfactory organ be destroyed with acid, the skin heals over the part, but the special epithelium and the nostrils are not reproduced; but in a conger in which the olfactory organ had been only partially destroyed, the plates of epithelium were found to be regenerating from the edges of the olfactory tissue which had remained undestroyed.

\section{Sense-organs of the Mouth and Skin.}

The scales and skin generally of fishes are supplied with remarkable sense-organs, which resemble the taste-buds of higher forms. These organs have been fully described and figured by Merkel in his monograph, Ueber die Endigungen der sensiblen Nerven in der Haut der Wirbelthiere (Rostock, 1880). In the course of these investigations a good deal of the ground covered by Merkel's work has been gone over, and to it there is little to add. It will be profitable, however, to mention those facts which specially concern the purposes of the present inquiry, and to describe the characters of some of these organs in forms which have not been investigated by Merkel.

Such organs consist essentially of clusters of long cells arranged together to form a bulb-shaped body, of which the apex is not covered by cuticle, but projects on the surface of the skin. The base of the bulb may be in contact with the basement-membrane of the skin, or may be separated from it by several layers of cells of the lower layer of the skin (cf. figs. 13 and 14). Into this base a nerve enters. Such an organ may be large and visible to the naked eye, as in the pharyngeal walls of most fishes, or it may consist of only a few such cells and be extremely minute. These minute "taste-

* Viz. P.platessa (the plaice), $P$. flesus (the flounder), $P$. limanda (the dab), $P$. microcephalus (the lemon sole of the east-coast fisheries). 
buds" are found in clusters on the large papillæ which occur on the gill-bars of the dog-fish (as observed by Merkel), of Cottus, and many other forms. The whole sense-organ may be placed on the general surface of the skin, or it may be depressed into a pit or elevated on a papilla, according to its situation and the animal in question.

The cells forming these sense-organs consist of a very long, narrow cylindrical head, which is external, an internal enlargement in which the nucleus lies, and a tail passing into a fibre of varying length ( $v$. fig. 15).

These sense-organs have a general resemblance to those of the lateral line, but the cells of which they are made do not appear to bear a hair on their peripheral buds, as those of the lateral line do.

I have examined them in the following forms, and have found them on the parts stated.

Bream (Pagellus centrodontus). On the palate.

Bullhead (Cottus scorpius). On the palate and on the papillæ of the gill-bars.

Gurnards (Trigla). On the palate and not on the fingers of the pectoral fin.

Pogge (Agonus cataphractus). On the villiform tentacles beneath the head.

Wrasses (Labridx). On the palate as patches of minute senseorgans surrounded by ridges of skin.

Grey mullet (Mugil). On the palate and in great numbers upon the fleshy thickenings in the pharynx; also in rows upon the white rugæ which form the anterior borders of these thickenings.

Pollack (Gadus pollachius). On the lips and palate (a few).

Pouting (G. luscus). On the lips, palate, barbel, and pelvic fins in great numbers.

Whiting (G. merlangus). On the lips and palate.

Rocklings (Motella). On all the barbels, pelvic fins, ${ }^{*}$ and palate.

Blenny (Blennius gattorugine). No sense-organs were found on the tree-shaped processes, which stand up from the anterior nostril and from the orbit. As these are parts which might have been expected to bear such organs, mention should be made of their absence.

Plaice (Pleuronectes platessa). On the palate.

Dab (Pleuronectes limanda). No sense-organs were seen on the palate.

Sole (Solea vulgaris). Contrary to the natural presumption, the

* In the last number of this Journal I stated that the pelvic fins of the rockling bore no organs of special sense. In specimens since prepared with gold chloride they are easy to see. 
villi on the lower (left) side of the head do not bear sense-organs, though, as $\mathrm{Mr}$. Cunningham informs me, such organs are found between the villi.

Conger (Conger vulgaris). On the outer and inner lips and palate.

Eel (Anguilla vulgaris). On the tongue and lips and on the skin of the tubular anterior nostril.

Dog-fish (Scyllium canicula). On the tongue and palate and in groups on the papillæ of the gill-bars.

Torpedo (Torpedo marmorata). No opportunity of dissecting this torpedo occurred, but these organs should be looked for on the papillæ bounding the spiracle of this species, in which place their occurrence would be interesting.

It is of course not suggested that these organs do not occur also on other parts of the animals named, as such structures are very generally distributed among fishes.

The nature of these structures is sufficiently shown by the figures. Upon the lips of the conger two types are found, of which the most usual is shown in fig. 13. The sense-organ is here seen to lie on the general surface of the skin, which is very thick. Below the sense-organ a narrow channel passes up through the whole thickness of the skin, and in this the nerve travels up to the senseorgan. The other type of sense-organ found in the same situation is precisely similar, except that it does not lie superficially but at the bottom of an open pit, depressed below the surface of the skin.

The nerve-supply of the sense-organs of the pharynx of the mullet (Mugil), \&c., and of the barbels of the rocklings (Motella), \&c., differs from these in that the skin is not channelled for the passage of the nerves to them. On the contrary, the fibres, after leaving the nerve-trunks, pass bodily through the basement-membrane and amongst the cells of the skin to break up on the sense-organs ( $v$. fig. 11).

\section{Senses of Fishes which seer their Food by Scent.}

Smell.-The majority of fishes seek their food chiefly if not entirely by sight, but a certain number hunt for and recognise it by the sense of smell alone, while a few species are also aided in seeking by special organs of touch. The following is a complete list of the fishes which have been observed by me to show consciousness of food which was unseen by them; and, as will be hereafter shown, there is evidence that they habitually seek it without the help of their eyes.

Protopterus annectens.

Rough dog-fish (Scyllium canicula).
Nursehound (Scyllium catulus). Skate (Raia batis). Conger (Conger vulgaris). 
Eel (Anguilla vulgaris).

Three-bearded rockling (Motella tricirrata).

Five-bearded rockling (Motella mustela).
Loach (Nemacheilus barbatula). ? Sucker (Lepadogaster Gouanii). Sole (Solea vulgaris). Little sole (Solea minuta). Sterlet (Acipenser ruthenus).

To this list may almost certainly be added the remainder of the Raiidx, together with the angel-fish (Rhina squatina) and torpedo. Unfortunately, however, the examples of these forms living in the tanks at Plymouth have never become thoroughly at home, and still (November, 1889) take food reluctantly. In fact, the skates have for many months subsisted entirely on shrimps, and very rarely take notice of other food; but owing to the kindness of Mr. Wells, the superintendent, I had an opportunity of seeing the habits of the skate under more favorable conditions at Brighton.

Of the fishes in this list the conger, rocklings, sole, and rough dogfish were the most frequently and minutely watched.

There are many points of resemblance in the habits of the various animals mentioned above, and some general observations may be made with regard to them collectively before pointing out the special features of interest in the natural history of each. In the first place they are all more or less nocturnal animals, and (? sterlet and Protopterus) remain in hiding by day, many of them being furnished with special modes of concealment. For example, the conger and the rocklings live in holes in the rocks, the eel and Protopterus in mud, the sucker and the loach under stones, while the sole lies completely buried in the sand, the eyeballs alone being exposed. When left to themselves they generally lie motionless until dusk, when they begin to swim about with more or less activity. If, however, while they are lying thus hidden the juice of food-substances (such as squid or pilchard) is poured into the water, they come out and feel about for a considerable time, clearly perceiving the odour. The dog-fish, conger, and eels feel for food with their noses, Protopterus with its pectoral and pelvic fins, the rocklings with the barbels and pelvic fins, the loach with its barbels, and the sole with the villi on the left (lower) side of its head.

None of these fishes ever start in quest of food when it is first put into the tank, but wait for an interval, doubtless until the scent has been diffused 'through the water. Having perceived the scent of food, they swim vaguely about and appear to seek it by examining the whole area pervaded by the scent, having seemingly no sense of the direction whence it proceeds.

Though some of these animals have undoubtedly some visual perception of objects moving in the water, yet at no time was there the slightest indication of any recognition of food-substances by sight. 
The process of search is equally indirect and tentative by day and by night, whether the food is exposed or hidden in an opaque vessel, whether a piece of actual food is in the water or the juice only, squeezed through a cloth, and, lastly, whether (as tested in the case of the conger and rockling) the fish be blind or not. On the other hand, if the olfactory epithelium is destroyed in the rockling or conger, the animal does not leave its hiding-place to hunt, though it seizes food placed near its face. Stones or other objects rubbed with food attract these fishes as much as food itself, and when very hungry they will snap at such uneatable substances, though they are rejected after being taken into the mouth. I saw no reason to suppose that any of these animals have the instinct of following a scent (as a prawn seems to do to some extent), though they always stop to examine bodies upon which food has lately rested. The scent of the food does not seem to remain long in the water, and apparently the scent of the surface of the food itself is dissipated or decomposed in a short time; for when, for instance, a piece of squid is not found after searching, it often happens that the fishes give up and retire, but will come out again in quest if the same piece of squid be taken out, cut in half to expose a new surface, and put back. None of the fishes were ever seen to hunt for more than about fifteen minutes unless the scent was renewed. It is difficult to estimate the distance to which a scent can be diffused in the water, but it is likely that, in water which is not rapidly moving, its virtues are destroyed before it has been carried far. There is, I think, no reason for supposing that scents are diffused through the water otherwise than by currents. This is most easily tested by experimenting with shrimps in a large shallow vessel. The shrimps remain buried until the scent reaches them. When the water was not in motion, if food was gently dropped in, the shrimps gave no sign for an indefinite time, but on stirring the water they began to seek. The longest tank at Plymouth is about twenty feet long, and an interval of from five to ten minutes elapses before conger at one end are aware of the presence of food put in at the other.

The perceptions, then, by which these animals recognise the presence of food are clearly obtained by means of the olfactory organs, and apparently exclusively through them. I was particularly surprised to find no indication of the possession of such a function by the sense-organs of the barbels and lips, or by those of the lateral line. As has been already described, the pelvic fins and barbels of the rocklings (Motella) and the lips, \&c., of most fishes bear great numbers of sense-organs closely comparable in structure with the taste-buds of other vertebrates. No one who has seen the mode of 
feeding of the rockling or pouting (Gadus luscus) can doubt that these organs are employed for the discrimination of food-substances ; but the fact already mentioned, that the rockling in which the olfactory organs had been extirpated did not take any notice of food that was not put close to it, points to the conclusion that they are of service only in actual contact with the food itself.

Sight.-In view of the fact that these fishes do not habitually recognise food by sight it would be especially interesting to determine what part in their economy is played by visual perceptions. Though nocturnal animals, they all have functional eyes, which in the conger, skates, and dog-fishes are as well developed as those of other fishes (v. p. 228). In the angel-fish, torpedo, and soles the eyes are, however, of small proportional size. Nevertheless, with the exception of the dog-fish and skates, in which the pupil is covered in daylight by the iris, there is nothing to suggest that there is any difference between the eyesight of these forms and that of other fishes. Positive evidence as to the class of objects which they distinguish is difficult to obtain owing to the general absence of facial or other expressions among fishes; and it should always be remembered that the fact that animals take no notice of objects is no proof that they do not see them. For example, wrasses, mullet, and other fishes with excellent sight take no notice of a handkerchief suddenly flipped against the glass of the tank in which they are, which would scare away a terrestrial animal ; but it is perfectly certain that they see the handkerchief, for they will snap at a worm hanging by a thread or sticking to the outside of the glass. Similarly they take no notice of a straight wire held up and waved outside the tank, but if the wire be bent into a sinuous curve like the body of a swimming worm they (pollack) will often dash at the glass in the attempt to seize it. It would appear, however, that fish are by no means slow at gaining knowledge of this kind. A curious instance of this occurred in the case of the rockling: (Motella tricirrata). When I first began to observe the mode of feeding of this fish I was inclined to believe that it did not see worms, \&c., thrown in for food. As mentioned above, it does not come towards them until they have been for some time in the water, and then, moving its head and fins, it swims wildly about until it comes in contact with the food, even though it be hanging freely in the water directly in the line of sight. But one of these fishes which has been living for some months in a shallow tank has been constantly fed by persons leaning over the top; and now when hungry not only comes up and splashes about on the surface of the water as soon as any one approaches, but will lift its head out of the water to snap at the fingers held above the surface, which it obviously sees and recognises. When last ob- 
served, however, it still did not appear to have learnt to recognise a worm swimming in the water, but only the presence of the person feeding it. When it is remembered that this fish naturally hunts by scent, the acquirement of this new instinct seems somewhat remarkable, and suggests that it is not the vision which is defective, but the power of appreciation. Being a nocturnal animal, it must be supposed to have never seen food, or to have seen it so rarely that it made no impression on it. These considerations suggest the possibility that these fishes may in the course of time learn to distinguish food by sight as they are now habitually fed by day.

There can be no doubt that soles also perceive objects approaching them, for they will bury themselves if a stroke at them is made with a landing net; yet they have no recognition of a worm hanging by a thread immediately over their heads, and will not take it even if it touch them, but continue to feel for it aimlessly on the bottom of the tank, being aware of its presence by the sense of smell. Soles, eels, and rocklings, moreover, have a clear appreciation of light and darkness being always buried or hidden by day (unless food is thrown in), but swimming freely about the tank like other fish at night. When thus swimming at large they bury or hide themselves if a light be flashed on them. Conger and loaches have some appreciation of moving objects, and occasionally snap at them, but their perceptions are extremely vague, as may be shown by watching their attempts to take a piece of food trailed through the water with a line. Their movements altogether are suggestive of a blurred perception, and perhaps it may be that their eyes are capable of distinct vision under greater pressure or in less light or at a greater distance. That greater pressure might produce an effect is very possible, but on watching their movements at night with a dark lantern, or in a tank from which the light was screened, there was no perceptible difference in their aptitude in discovering food.

None of these fishes have much apparent difficulty in avoiding obstacles, but as large obstacles seem to be easily avoided by the same animals when deprived of sight, it may be doubted whether this perception of obstacles is not as much obtained by general sensation, especially of currents, as it is by sight.

As to the sight of the sterlet no experiments have as yet been made.

Touch.-In the rocklings, as mentioned in this journal (N, S., i, 2, p. 214), the pelvic fins are developed as special tactile organs, and are used in the mode there described. By these organs they are not only able to distinguish food-substances alone, for a rockling on brushing with its pelvic fins against a piece of glass or a stone smeared with vaseline, turns and examines it, clearly remarking the peculiar feel of such surfaces. 
Filamentous fins similar to those of the rocklings are found in Protopterus annectens, in which both the pectoral and pelvic fins have this structure. Through the courtesy of $\mathrm{Mr}$. Wells I was enabled to watch the mode of feeding of this fish in the Brighton Aquarium. The fins are used in a manner somewhat different from that of the rockling, which merely extends the fins at right angles to the body, and swims wildly about until they happen to touch the food. Protopterus, on the other hand, whips with them on the bottom of the tank until the food is struck. The tail also of this fish is, perhaps, used for seeking food, but this was not clearly established.

In connection with the sense of touch, the mode of feeding of the soles may be fitly described. The sole feeds in a manner peculiar to itself, and unlike that of any other fishes which have come under my notice. As already stated, it remains buried by day, and generally speaking, if the sand be fine its body is completely covered. When shrimps or pieces of other food are thrown in, after an interval the soles perceive it; they then give a writhing jump or succession of jumps from the bottom of the tank, and begin to search on the ground. When searching for food the upper (right) side of the sole is nearly always covered with a coating of sand so uniform that little or none of the skin can be seen. There can, I think, be little doubt that this sand sticks to the body owing to an outpouring of mucus on the surface of the skin, which probably occurs when the smell of food is perceived, and is comparable with the watering of the mouth in ourselves.* This covering of sand is no doubt dusted over them by these energetic movements, but it only adheres when the sole is searching for food. At night, for example, when the soles are active, they carry no sand. The coating of sand must be pretty firmly attached, for if a sanded sole is made to swim rapidly the covering of sand remains.

In seaching for food the sole creeps about on the bottom by means of the fringe of fin-rays with which its body is edged, and thus slowly moving, it raises its head upwards and sideways, and gently pats the ground at intervals, feeling the objects in its path with the peculiar villiform papillæ which cover the lower (left) side of its head and face. In this way it will examine the whole surface of the floor of the tank, stopping and going back to investigate pieces of stick, string, or other objects which it feels below its cheek. As already stated, the sole appears to be unable to find food that does not lie on the bottom, and will not succeed in finding food suspended

* At the moment when a conger lying still first perceives the smell of food, he generally shakes himself, and takes a gulping inspiration, freeing a variable quantity of mucus from the skin and pharynx, which floats up through the water, owing to small bubbles of gas which are enclosed in it. 
in the water unless it be lowered so that the sole is able to cover part of it with the lower side of its head, when it seizes it at once. These remarks apply to the common sole (Solea vulgaris), to Solea minuta, and probably to all the other species, but none of these have lived in the aquarium long enough for observation.

The fact that soles are hardly ever taken with a hook is no doubt due to this manner of feeding; for the bait is not allowed to lie on the bottom except in long line fishing, which is done with large hooks only and on rough ground. If long lines with small gear were laid on the soft ground where the soles live, it is by no means unlikely that they would be taken. In this case it would probably be found to be the most rational way of catching soles.

The sterlet and loaches on perceiving the smell of food hunt for it with their noses and barbels on the bottom. The barbels of the sterlet do not appear to be moveable as those of the pouting, \&c., are, and the specimens watched at Brighton did not shovel with their noses, but protruded their remarkable jaws, and appeared to make random bites at the bottom when food was thrown in.

\section{The Senses of Fishes which seek their Food by Sight.}

The majority of fishes belong to this class. The following is a list of all the species which have been observed in the Aquarium either at Brighton or Plymouth to feed in this manner. Many others-as, for example, the Salmonidæ and Scombridæ-might have been added, but I have only given the names of those which have come under my own observation.

Bass (Labrax lupus).

Bream (Pagellus centrodontus).

Bullhead (Cottus scorpius).

Red gurnard (Trigla cuculus).

Grey gurnard (Tub) (T. hirundo).

Pogge (Agonus cataphractus).

Weever (Trachinus vipera).

Horse-mackerel (Caranx trachurus).

Herring (Clupea harengus).

Dory (Zeus faber).

Boar-fish (Capros aper).

Goby (Gobius minutus).

Dragonet (Callionymus lyra).

Lump-fish (Cyclopterus lumpus).

Blenny (Blennius pholis).
Gattorugine (Blennius gattorugine).

Butter-fish (Centronotus gunnellus).

Grey mullet (Mugil chelo).

Three-spined stickleback (Gasterosteus aculeatus).

Fifteen-spined stickleback ( $G$. spinachia).

Spotted wrasse (Labrus maculatus).

Rainbow wrasse (Coris julis).

Pouting (Gadus luscus).

Whiting (Gadus merlangus).

Pollack (Gadus pollachius).

Cod (Gadus morrhua). 
Turbot (Rhombus maximus). Brill (Rhombus levis). Müller's topknot (Zeugopterus punctatus).

Plaice (Pleuronectes platessa). Dab ( $P$. limanda).
Flounder (P. flesus).

Shorter pipe-fish (Nerophis cquoreus).

Worm pipe-fish ( $N$. lumbriciformis).

Sight.-The sense of sight in these fishes is developed in various degrees. In some, as in the bream (Pagellus), the eyes are practically fixed; while in others, as in the pipe-fishes (Syngnathidæ), dory (Zeus faber), and wrasses (Labridx), the eyes are capable of considerable movement, and are used independently like those of the chameleon. None of the fishes observed appear to distinguish food (worms) at a greater horizontal distance than about four feet, and for most of them the vertical limit seemed to be about three feet; but the plaice at the bottom of the tank perceived worms when at the surface of the water, being about five feet above them. Though the distance of clear vision seems to be so small for objects in the water, many of these fish (plaice, mullet, bream) notice a man appearing on the other side of the room, distant about fifteen feet from the window of the tank. When hungry they swim up to the side of the tank and show great excitement if a person approaches. The same may be seen in the case of Octopus at Brighton, which, when the crowd collects in front of the tank, by its rapid and excited movements shows that it recognises the signs of approaching feeding-time.* The range of sight of fishes on the whole appears to be short. The sight of the wrasses (Labridx) in particular is plainly adapted for vision at very close quarters ; for the habit of these fishes is to search for their food by minute examination of the bottom, weeds, \&c., after the manner of insectivorous birds.

None of the fish seem to get any lasting appreciation of the nature of the plate-glass wall of the tank. The same fish will again and again knock its head against the glass in trying to seize objects

* In this case there is some doubt as to whether the Octopus does not recognise feedingtime by the help of its internal sensations. I have as yet had no opportunity for accurate experiment; but Mr. Wells tells me that both the Octopus and conger begin to swim about at feeding-time, whether any one is at the top of the tank or not. The conger are fed on alternate days, and Mr. Wells assures me that they distinguish these days, and do not get excited on the off days. On two occasions only I have watched them myself. The first was not a feeding-day, and they were not swimming about; but they certainly were actively moving to and fro on the second visit, which was one of their feeding-days, as also were the eels, which is still more surprising in view of their exceedingly nocturnal habits. So far, therefore, as my observation went, it quite bore out the statement of the superintendent. The fishes at Plymouth have not hitherto been fed with regularity, as their meals have to be arranged with a view to other experiments, so that no conclusions on this point can be drawn from them. 
moving on the other side. Any small oscillating substance may attract them, such as a button dangling to a thread; and pollack ( $G$. pollachius) often snap at even a curl of smoke from a pipe. After repeated attempts to take food on the other side of the glass they will desist; but some of the oldest inhabitants (plaice, pollack, and bream), which have been living in the aquarium for about a year, will perseveringly try again the next time. Fishes brought newly to the aquarium injure themselves by trying to escape through the glass, and I have seen gurnard fretting themselves for hours against it when the water of the tank has been made turbid by pouring in sand, being evidently of opinion that it is a way into clearer waters. It may here be suggested that perhaps the result of the famous experiment of Möbius has been wrongly interpreted. The story runs that pike, having lived for some time in a tank separated by a glass plate from another in which small fish were living, desisted from trying to catch them, and on the glass plate being removed never attempted to do so. The suggestion is that the pike had come to believe these particular fish to be under special protection. While this may be so, it is nevertheless a fact that fish, like other animals, having grown accustomed to the presence of forms which they would naturally eat, do not molest them. On one occasion several pollack were put into the congers' tank at Plymouth, and in the morning two only remained, but these two continued undisturbed for a long period; and other similar cases have been observed. The explanation should perhaps be referred to that paradoxical instinct which is widely developed among animals of many kinds, in obedience to which they occasionally do not eat or molest those with whom they are constantly associated. It is, of course, this unexplained instinct upon which the "happy family" of the travelling showman is constructed. Probably it is closely akin to many feelings and superstitions of which we are ourselves conscious, and which have received inadequate but rational explanations.

Many of the actions of fishes are of this paradoxical character. It is a common thing, when two fish swim up to the same worm, for the foremost to retire in a nervous way, leaving the worm for the other; and this quite independently of the relative sizes of the individuals. A small cod whose gills were injured lived for some time in a tank with bream and bass. This fish rarely if ever ate anything, but always swam up for a moment to each piece of food as it was put in, and then left it. When the cod approached, the bass, though many times his size, used to fall back, and return to eat the food when the cod retired. This process would be repeated again and again, and happens so often in the case of bream and bass that it appeared almost the rule for a fish to refuse at food if another 
fish came up behind it. Sticklebacks and blennies, on the other hand, snatch pieces from each others' mouths like hens; so also do eels and other fish which hunt by scent. Conger, in particular, fight lustily over their food; and though they may hesitate for some time to take a piece of food which is tainted, or a substance of otherwise doubtful scent, yet they bolt it at once if another conger or a crab begins to examine it or pull it away; afterwards, if need be, they reject it. These remarks illustrate the necessity for caution in making deductions as to the likes and dislikes of fishes from scanty observations.

It has been mentioned that various fishes differ in their powers of seeing things above or on a level with them, but far more remarkable is the difference in the degree to which they are able to see downwards. Of the fish mentioned above the following were never seen to eat food after it had fallen to the bottom of the tank :-bass, bream, dory, boar-fish, lump-sucker, and pollack. The pollack are particularly interesting to watch in this connection, appearing absolutely unable to find objects which have reached the ground. It may be that their vision is such as not to admit of the perception of things below them, or it may be that the whole surface of the bottom is to them indistinct and blurred, or possibly the protruding lower jaws of these fish prevent them from picking up objects lying on the ground, but certainly they never seem to attempt it; and if they fail to catch worms, shrimps, \&c., as they are falling through the water they give up at once. It is to be regretted that the majority of the fishes living at Plymouth are littoral forms, and such as are accustomed to live and feed on the bottom ; for it is likely that there are many other fishes which are similarly unable to find food which is below them. It may be mentioned that, in addition to those given above, it is rarely that mullet or small pouting find food on the bottom. Pouting of larger size, however, use their pelvic fins for this purpose, as hereafter described. In fact, it is probably exceptional for an ordinary freely swimming fish, which hunts by sight, to seek food which is not in suspension; for nearly all those that have the power of feeding on the bottom either possess organs of touch, as the gurnard and pouting, or moveable eyes, as the wrasses and pipe-fishes, or else have the eyes peculiarly placed, as the flat fishes and blennies.

The mode of feeding of the dory and pipe-fishes is sufficiently singular to call for special remark. These animals are both provided with transparent, vibratile membranous fins. In the dory these are caudal, anal, and pectoral, while in the pipe-fishes the pectoral and dorsal only are thus developed. By the oscillation of these the animal approaches its prey without making any general movements, and in fact stalks it. The flattened body of the dory is most in- 
conspicuous when seen from in front, as is that of the pipe-fishes when seen end-on. The dory feeds on small fish, working up to them in this way very slowly and with precision, like a man working up to game in open country where there is no cover. On getting within range, which is some inches from the prey, the immense protrusible jaws are shot out, and the fish is drawn back with them into the mouth. When the dory sights his prey the whole aspect of the fish changes. The curious brown markings on the body, which are at times scarcely visible, blush up and become dark. Of these the most conspicuous is a wide dark band passing down the middle of the nose and continuing between the jaws; this dark stripe gives the fish a most singular appearance when seen from in front. In the case of the pipe-fish, which feeds largely on small shrimps, the face is drawn out into the well-known pipe-like process which is gradually pushed right up to the victim, who would be alarmed and escape at the approach of a more clumsily organised fish. During this proceeding the pipe-fish frequently comes forward on its ventral surface.

None of these sight-hunting fishes while living in the tanks appear able to see their food by night, or even in twilight; worms thrown in after dark fell through the water unnoticed. It did not appear that this was due to reluctance on the part of the fish to eat by night, for on some occasions pollack took worms by night when the light of a bull's eye was turned on them so that the fish could see them. In view of this fact it would be interesting to see if fishes would take an object made luminous with Balmain's luminous paint or otherwise. I made experiments with pieces of india-rubber and with twisted glass tubes filled with luminous paint and sealed up, but none of the fish took any notice of them. Perhaps, however, such fish as mackerel might be attracted by similar objects trailed along: in the open sea by night; for so many of the animals which are preyed upon by fishes are phosphorescent, that it is likely that some at least are accustomed thus to recognise them.

In view of the brilliant colours which are so common among marine animals it would be highly interesting to get some idea of the colour sense of fishes, but so far my results have been chiefly negative. In the first place I endeavoured to find out if light of any particular colour were invisible to soles and other nocturnal fish which, as already stated, swim about in the dark, but hide themselves when a light is turned on them. My experience was that their behaviour did not appreciably differ whether the light was red, blue, or green ; and in fact they (eels and soles) seemed to be conscious of and to aroid coloured light almost as much as plain light. On the other hand, the pupil of Eledone contracts much less for red light than for other colours; and the larvæ of the lobster, which swim towards a light, 
leave red for yellow, and yellow for green, preferring blue-green to violet and to all the coloured glasses with which they were tested. As these animals seek the light it may be supposed that the bluegreen seems to them the most intense. Whether, as happened in the case of Sir John Lubbock's experiments with ants, any of these animals perceive vividly the ultra-violet rays I cannot say, as I had not the necessary appliances.

As it has been suggested that the bright colours of animals may have a protective value, which suggestion has recently been extended by Garstang (Journ. M. B. A., N. S., i, 2, p. 175) to marine animals, I endeavoured to ascertain in the case of mullet whether bright colours have any such deterrent power. The mullet in question were a shoal of small fry about one and a half inches long. They were accustomed to eat minced worms off a slate slab. Upon the slate slab I arranged a number of brightly coloured tiles, some having plain and others mottled surfaces, and the minced worm was laid on these. The tiles were dark red, white, pale blue, dark blue, and mottled greenish brown. On several occasions the food was first cleaned off the pale blue and the white tiles upon which it was most conspicuous, and next off the mottled ones. The food on the dark blue and dark red tiles generally remained the longest, but was eventually eaten. On the whole it seemed to me that the fish distinguished between the tiles, but there was nothing to suggest that they were afraid of any of them. Certainly the bright colour of the pale blue tile did not seem to trouble them. It would perhaps be worth while to make a similar experiment with some of the glass models of anemones, \&c., which are now obtainable, in order to test whether the colours, per se, have any deterrent effect.

It has been stated above that pollack will snatch at a wire curved in to the shape of a worm when it is held up outside the tank. The same wire when painted white, or bright yellow, or blue, proved equally attractive.

Smell.-It was stated above that the great majority of fishes hunt their food by sight, and there is a good deal of evidence that it is sought for by sight alone. None of the fishes mentioned on pp. 24:1-2 show symptoms of interest when the juice of food-substances is put into the water. They will attempt to take worms, shrimps, pieces of fish, \&c., which are lowered into the water inside a glass tube, or which are simply sticking to the glass window of the tank. When hungry they are unable to find food in the dark, while by day they will seize uneatable substances which are quickly moving in the water. This evidence goes to show that the sense of smell plays little or no part in helping them to discover their food. On the other hand, both pollack and whiting, when their first hunger is satis- 
fied, swim under the food so as to touch it with their noses and presumably smell it ; and this gesture is often performed by individuals in which the olfactory organs have been destroyed, probably by force of habit. Mullet examine food by sucking water from it, and bass, bream, \&c., touch doubtful food with their lips before seizing it. Plaice, turbot, blennies, and wrasses do not seem to make any preliminary examination of the flavour before taking food into their mouths. The importance of the olfactory organs to such animals as these is therefore obscure.

The range of tastes and scents which fishes are capable of perceiving seems to be very small. Conger are equally willing to eat a piece of squid or pilchard if it is covered or smeared with spirit, trimethylamine, turpentine, iodoform, camphor spirit, cheese of various sorts, anchory extract, or Balanoglossus, * as if it had been unpolluted. On the other hand, they will refuse cooked or tainted food and food which has been soaked for a few moments in dilute acids. The same remarks apply generally to the other fishes. None of them paid the slightest heed to stones or other objects covered with any of the substances mentioned. I was particularly surprised that none of the fishes in the tanks took notice of rogue-the fermented roe of the cod, which has a most powerful odour, and is used with great success to attract sardines by the fishermen of Brittany -but of course none of my fish were Clupeidx. It is supposed by the sardine fishermen that the odour is of great importance, and must be of the right quality. Hence it may be imagined that it does not merely attract the sardines by sight.

In this place mention should be made of the fact that some of the Gadidx, which are, generally speaking, day feeders, are sometimes taken with a bait at night. At certain times of the year this is the recognised mode of catching hake (Merluccius vulgaris), while occasionally whiting are so taken. In both these cases the bait is sent down about halfway to the bottom, and not, as usually, to within a fathom of it. I was assured by fishermen that this mode of feeding is a most exceptional thing with whiting, and is supposed to be connected with the continued prevalence of calms, for under ordinary circumstances whiting-catching is not continued after dusk. In addition to these instances it sometimes happens that large pollack are taken on ground-lines by night. Whether in these cases the food is found by sight or by smell there is no evidence to show, for both the pollack and the whiting living in the tanks seem unable to find food in

* As the disgusting smells emitted by various species of Balanoglossus may be thought to be protective, I tested various fishes with pieces of a single damaged specimen of $B$. salmoneus which was dredged in Plymouth Sound. It was refused by both mullet and wrasse after trial, but was eaten by a sole and by a plaice. 
the dark. Taken in connexion with the fact that this habit of whiting is supposed to occur in fine weather, it is possible that the fish are guided by the phosphorescence either of the bait itself or of the animals carried past it by the tide. Mention should also be made of the fact that trout are often taken with a worm at night.

Touch.-Of the fishes which seek their food by sight some are provided with barbels, as the pouting and the cod, while a few have special tactile organs, as the gurnards, and again the pouting. When the pouting is hungry it takes its food promptly, without hesitation, but when it has had about enough it frequently erects the barbel so that it projects forward and touches the food with it, probably thus tasting it. In the Brighton Aquarium I saw that the pelvic fins of the pouting are used just as those of the rockling are, the fish swimming with them set at right angles to the body and touching the ground, but those at Plymouth were not seen to do this. The latter are much smaller specimens, which fact may possibly account for this difference in habit.

The fingers of the pectoral fin of the gurnards are certainly used in the search for food. Although the gurnards have good sight and will swim up to a bait, they are chiefly bottom-feeders, and move about with these fingers, half walking and half swimming as they seek their food. On touching a worm with the fingers they stop and scratch it about for some moments, as though raking it out of the sand, and then suddenly turn and snap it up. Though the fingers are thus employed, the gurnards often take food off the bottom without touching it with the fingers. I did not succeed in seeing the gurnards feed by night, but it is quite possible that they may do so.

I was surprised to find that the pogge (Agonus cataphractus) did not appear to use the filamentous villi of the lower side of the head for finding food. These villi are developed to a great degree, and bear sense-organs which suggest that they may be used for this purpose; but though repeatedly watched, it was never seen to seek food otherwise than by sight. Thinking that these structures might be of use to it in discovering food buried in the sand, I made some trials, but the fish never seemed to recognise the presence of the buried food.

General Sensation.-The power which fishes possess of avoiding obstacles even when deprived of sight is very remarkable. For example, a bream in which the cornea has been rendered opaque, after recovery from the shock does not run into the sides of the tank, but swims round in a circle avoiding them. If a large obstacle, such as a glass plate, is put in the way, the fish avoids that also. But it would seem that this is because such an object cannot be brought into position without causing a disturbance in the water which the 
fish perceives. For if wire rabbit-netting or straight wires are gently lowered while the fish is at the other part of his circle, he does not avoid them on returning the first time. After colliding with such an object, though very gently, the fish seems to lose its balance, and does not swim upright for some seconds after, lying over generally towards the left side. If the wires are left in place the fish does not again run into them, but swims in a reduced circle. The sensibility of these fishes to movements in the water must be exceedingly delicate ; for if a straight wire is put in the path of a blind fish it will be avoided if the finger only is kept on the top of the wire, though it does not avoid it if the wire is standing by itself. The same is true of pollack which had become blind from disease (apparently of the nature of cataract, to which fishes in captivity are very liable). It has been held by some observers that the senseorgans of the lateral line are of importance to the equilibration of the animal. Apart from the difficulties presented by the structure of these organs, which closely resemble taste-buds, it must be held that the case of the flat-fishes is practically conclusive against this view. For in the flat-fishes not only do the lateral lines retain the same position relative to the symmetry of the animal that they occupy in other fishes, but in those fishes (e.g. the dab, \&c.) in which the course is peculiarly curved, this curve occurs equally on the upper and under surfaces. But as the flat-fishes swim in a plane at right angles to that of ordinary fishes the two lateral lines come to lie in the same vertical planes, and can therefore hardly be supposed to assist in equilibration. The fact that a fish in which the lateral nerve has been severed is unable to swim uprightly scarcely bears on this question, for almost any severe injury upsets the equilibrium of a fish.

Shoaling.- It was suggested to me by Professor Lankester that inquiry should be made as to the manner in which fishes keep together in shoals, and especially whether they follow each other by sight or otherwise. The only shoaling fish which was living in quantity in the tanks at Plymouth is the grey mullet. By day the whole shoal of about fifty little ones stays together more or less. Sometimes it divides into two or three shoals, but they run closely together if alarmed.* At night they lie on the surface of the water, and seem not to swim about as a body, nor are their heads all pointing one way as they generally are by day. The shoal seems at no time to have any leader, but will sometimes follow the front fish until one

* This instinct of packing together when afraid seems to be general among fishes which move in shoals. Mr. Dunn tells me that the proverbial phrase, "as close as hakes in a hoop," is derived from the fact that such fishes huddle together when surrounded by a net. Shoals of pilchard, herring, \&c., also pack together when attacked by sea-birds. 
of those that are behind makes a dart elsewhere, when the whole shoal turns round and follows. They certainly have no tendency to follow the largest fish in the shoal, or indeed any fish in particular. Similarity in size seems to be usual in these shoals. In one of the tanks there are two mullet which have been there for about a year, and are now about three inches long. They live apart on the ledge of the overflow, and never consort with the other mullet, which are about six inches in length. When, however, some of this year's fish (three-quarter inch) were put in, these two immediately swam out to them, and they all retired together into the overflow channel, where they afterwards remained habitually.

To the fifty small mullet in the long tank I introduced twenty more of rather smaller size, but of the same age, which had lived in another tank. The fifty at once ceased feeding, and huddled timidly away behind the stand-pipe, where they were joined by the new-comers. After a time the latter all left them in a body, thus showing that they recognised each other in some manner. They soon returned, however, and after staying together for a little a detachment of the new-comers again left, and so on; but on the following day the two shoals had amalgamated and fed together. Weakly fish never swim with the shoal, but keep apart-whether by choice or compulsion could not be determined.

Two specimens of horse-mackerel (Caranx trachurus), about two and a half inches long, put in in September, shoaled with the mullet, but the gobies never do so. In November on returning to Plymouth I found that one of the horse-mackerel was dead, and the other had left the mullet and moved about alone, but if alarmed it at once joined the mullet.

From the fact that the mullet do not move as a shoal at night, it may be so far inferred that they follow each other by sight alone, but it would be interesting to know whether other shoal-fishes travel at night. It may, in fact, be doubted whether such fish as pilchards habitually move about as a shoal at night. Of course drift-netting is carried on at night; but the nets are shot in places where the pilchards or herrings are known to be, and possibly the slight movements of the individuals and currents may take them into the net. That the shoals under some circumstances do not travel at night is seen by the use of the method of seeking pilchards known as "briming" for them. In this operation, which I have never seen, but which has been described to me by several fishermen, as the boat sails along, a man stands on the cuddy and stamps his foot at intervals. When the boat is among the pilchards, they are then seen by means of the "briming" or phosphorescence to dart away in all directions. Presumably, then, until disturbed by the noise 
they were lying at the top of the water, as the mullet were observed to do in the aquarium.

Hearing.-Several attempts were made to determine the class of sounds which fishes can hear. During the month of November some blasting operations were carried out on the premises of the Association, and particular notice was taken of the behaviour of the fish. The pouting scattered for a moment in all directions when the report came, but were quiet directly afterwards. The soles, plaice and turbot buried themselves. The conger drew back a few inches, as is their habit also when a light is turned on them at night, and generally on being disturbed. None of the other fishes were seen to take any notice of the report.

As mentioned in this Journal (N. S., i, 2, p. 217), satisfactory evidence was obtained that the creaking sound made by smearing a wet finger on the glass window of the tank was heard by a Lamellibranch (Anomia). For some time I was of opinion that the same sound was heard by some fishes (pollack, \&c.) which at once come to the spot and follow the finger. Mr. Wells, of the Brighton Aquarium, told me that his own observations led him also to believe this, especially in the case of bream, which come to the front in a body when this sound is made. Nevertheless, on further trials I saw no reason to suppose that the fish were not merely following the finger by sight, and I never saw them (pollack) attracted when the sound was made behind a screen of silk or weeds sunk in the water, and such a screen would scarcely interfere with the transmission of the sound. The movements of the bream at Brighton did not, however, resemble those of fishes trying: to catch a particular piece of food, but were distinctly suggestive of general expectation. Seeing that the case of the Anomia proves that sensible vibrations are thus actually set up in the water, it may be that they hear them. The sound made by pebbles rattling inside an opaque glass tube does not attract or alarm pollack; neither are they affected by the sharp sound made by letting a hanging stone tap against an opaque glass plate standing vertically in the water. If they see the stones in either of these cases they follow them, but if the glass is opaque they do not. When the wall of the tank is struck with a heavy stick they behave as described in the case of blasting. As might be expected, none of the fishes were seen to take notice of sounds made in the air. Various loud noises were tried, but soles, for instance, when exposed did not bury themselves as they do when the side of the tank is struck. Probably, therefore, they did not hear the noises. The stories, for example, quoted in Day's British Fishes, p. xxxviii, of fishes coming to be fed when a bell was rung, can scarcely be taken to prove that the sound of the bell was heard by them, unless it be clearly proven that the person about 
to feed them was hidden from their sight. The sound of the chopper which is also there mentioned in this connexion may have been communicated directly by the walls of the tank. There is no reasonable doubt that in the operation of "briming" for pilchards (v. p. 250 ), the sound made by the stamping of the foot is actually heard.

Though it may, therefore, be regarded as clear that fishes perceive the sound of sudden shocks and concussions when they are severe, it can scarcely be supposed that sounds of this nature play much part in their ordinary life, even if they occurat all. On the other hand, they do not seem to hear the sound of bodies moving in the water which they do not see. It may be remarked that the sounds emitted by fishes and Crustacea (dory, gurnard, crayfish, \&c.) are of a stridulating or grumbling nature. In addition to these $\mathrm{Mr}$. Wells called my attention to a peculiar snapping sound (audible in the room) which is made by large wrasses when feeding and biting with their strong jaws.

\section{Remarks on the Supply of Bait.}

The observations recorded above were made as a first step towards a practical solution of the difficulties which beset the bait question. It was felt that any attempt to find a cheap bait must be begun by getting a knowledge of the ways in which fishes find and recognise their food; and it was anticipated that when such knowledge should have been acquired, it would be possible to make use of it in a practical manner. Though the practical side of the subject was beyond the scope of this part of the investigation, it may be permissible to make a few remarks upon this aspect of the matter, and to indicate the lines of practical experiment to which these observations point.

The fishes which are chiefly sought by long-line fishermen on the south coast of England are conger, skates, and rays ; while elsewhere the most important fishes which are taken with a hook are cod and halibut (Hippoglossus vulgaris). The chief substances used as bait are-for the east coast of England and North Atlantic, the herring; for the Scotch fisheries, the whelk (Buccinum undatum) and the mussel (Mytilus edulis); on the south coast of England the squid (Loligo vulgaris) and the pilchard are most in demand; while in the Channel Islands Eledone is used in great quantity. Everywhere the supply of bait is costly, and at times it fails, owing to calms or bad weather. It is therefore important that some substance should be obtained or manufactured which is attractive to fishes, but cheaper and more regularly accessible than the natural baits at present used. 
In any attempt to prepare such a substance it is of the first importance to ascertain the mode by which fishes find and distinguish their food. As has been here set forth, satisfactory evidence was obtained that conger and the Raiidæ seek their food by smell. While I was at Plymouth no opportunity occurred of watching the habits of the cod, for only one injured specimen was obtained. It was quite clear that this fish saw exceedingly well, but whether or not the barbel or olfactory organs may not be used also in seeking food on the bottom or at night I am unable to say, but from experience of other fishes it is a priori unlikely that they are of great value as organs of search. The halibut is of course not found on the south coast, and has not come under my observation in the live state; but the structure of the fish, which closely resembles the plaice, suggests that it feeds by sight. This suggestion is strongly supported by the statement of Pennant quoted in Day's British Fishes (ii, p. 7) that on two occasions halibut had been known to take a sounding-lead. The fishes, then, which are sought by the North Sea fishermen and others differ from those upon which the Plymouth men most depend, for the former feed by sight and the latter by scent. As might be expected, therefore, the same bait is of different value in the two cases. For while in the North Sea the herring is thought to be the best bait, Plymouth fishermen scarcely think it worth their while to go to sea with it. At Plymouth, for catching conger fresh squid is thought to be the best bait, and fresh pilchard is by some considered as good as regards attractiveness, but as it has not the toughness of squid it does not stay on the hook so long. My own experience with conger in the tanks leads me to think that squid is also more attractive as a scent than pilchard is. In the absence of pilchard and squid, mackerel is used when abundant, but usually this fish is too dear to be in use as bait, and it certainly does not attract conger as much as squid.

The facts already given point to the conclusion that for the purposes of the conger and skate fishery the bait question may be solved in one of three ways : either-

(1) By extracting the flavour of squid or pilchard, and com. pounding it with some tough substance which will not wash off the hook; or-

(2) By finely dividing squid or pilchard and mixing it with some cheap substance, so as to make a little of it go further; or-

(3) By preserving squid or pilchard when abundant in such a manner as not to destroy its flavour and scent: of course this last method would only help the fishermen to tide over periods of scarcity of bait.

I have made some experiments in each of these directions, and NEW SERIES.—VOL. I, NO. III. 
perhaps a record of my experiences may be useful to those who intend to go on with the subject.

(1) This would no doubt give the most complete solution of the whole difficulty. I made some preliminary experiments with extraction by ether, and found that both from Nereis and from herrings after the ether had been distilled off, an oily fluid remained, which certainly attracted rocklings most powerfully, and caused them to snap at stones dipped in it. That obtained from herring also brought the conger out of their holes, but they did not show the eagerness that they do when seeking actual food.

Mr. Bourne has prepared a remarkable fluid by simple distillation of squid and water. This has a strong smell resembling that of cooked squid, and has stood for over a year without decomposition. It did not appear, however, that the fish noticed it at all.

By adding spirit very gradually day by day to mashed squid mixed with sea water which was kept warm, a good deal of the scent was extracted, and when the conger were very hungry a few c.c. of this extract poured into the tank sufficed to put them into a state of great excitement; they would seize rags which had been dipped in it, but I did not succeed in compounding it with any substance which they cared to eat. These results, though incomplete, are so far fairly encouraging.

(2) Many attempts were made to incorporate finely divided squid with gelatine. It seemed possible that if gelatine into which mashed squid had been stirred whilst warm and liquid, could be cast into sheets and dried, it might perhaps retain its flavour sufficiently to be eaten on being again softened with water. Consistency was given to these sheets of gelatine by stretching a sheet of butter-cloth in them when warm. When the conger were very hungry they would eat this substance with hesitation, and in the sea I caught an occasional fish (rockling and conger) with it, but it was by no means satisfactory, probably because each particle of squid was so coated with gelatine that its scent could not get out.

The next experiment was made by pouring melted gelatine into dishes smeared with mashed squid or mackerel, and then laying sheets of tissue-paper similarly smeared on the upper surface of the gelatine before it had set. When the gelatine was cold the paper was stripped off, and the gelatine remained covered on each side with a thin smearing of fish. The fish in the tanks ate this substance when fresh as readily as ordinary food, but it is unsuited to the purposes of fishing in deep water, as the coating of fish is washed off, and no doubt soon loses its scent. Probably the difficulty arising from the fact that the scent is soon destroyed on the surface of the 
food would prevent its being used in a finely divided form, however compounded.

(3) In experimenting with squid on a small scale I found that it could easily be preserved for about a month by cutting it open, cleaning and drying it with a cloth, and then powdering it with boracic acid and flour. This squid was apparently unchanged, and was in excellent condition for bait. Unfortunately, now that so many of the trawlers go away to the Bristol Channel, but little squid is landed at Plymouth.

Salted squid and salted pilchards are used, but are very unsatis. factory.

On a small scale pilchards were preserved for three weeks in the same way with boracic acid and flour, and were satisfactory as bait for conger. I succeeded also in catching mackerel at the time when they were feeding near the bottom (August and September) with preserved pilchard and preserved squid.* With the kind assistance of Mr. Matthias Dunn, of Mevagissey, I laid down several barrels of pilchards with boracic acid and flour as described, but for some unknown reason they did not answer. Though not decomposed, in a month's time they had become what is called by fish-curers " rusty," and their scent was that of cured fish rather than that of fresh. My experience with them on a small scale leads me to believe that with experience and precautions they might be kept with boracic acid in the dry state. Of course this preservation should be made with winter fish, which contain much less oil than summer fish. There is little hope that they could be preserved for bait in a solution of boracic acid, from the fact already mentioned that the scent of these thing's seems to be destroyed by contact with water.

In conclusion, I may repeat that the experiences here given suggest that the first step to a proper solution of the bait question for the south coast and Channel Island fisheries, where fishes which hunt by scent are caught, must be made by the extraction of the scent of squid or pilchards. Whether an artificial bait flavoured with such an extract would be useful in the fisheries of the North Sea, \&c., cannot be predicted, but if made of some bright or white material (as dough or china clay) it might probably prove equally attractive to fish which hunt by sight. At the same time it must be borne in mind that any artificial bait must be extremely cheap if it is to be preferred (in the North Sea) to herrings, which are to be had for a great part of the year. It would, moreover, be interesting to see

* When mackerel are fished for at anchor with a hand-line, these two baits are used together, a small piece of each being put on the hook. It is difficult to explain the reason. of this curious practice, but either bait alone is said to be of little use, which my own experience fully confirms as far as it goes. 
whether the conger, \&c., of the North Sea would take pilchard or squid, which they have probably never met in their ordinary experience.

\section{DESCRIPTION OF PLATE XX.}

Illustrating Mr. Bateson's paper on "The Sense-organs and Perceptions of Fishes ; with Remarks on the Supply of Bait."

Fic. 1.-Head of a dab (Pleuronectes limanda), nat. size, showing the position of the olfactory organ as seen when the skin is removed.

FIG. 2.-Diagrammatic representation of the right olfactory organ of the dab.

FrG, 3.-Outline of the face of a megrim (Arnoglossus megastoma), showing the left olfactory organ as seen when the skin is removed (nat. size).

FIG. 4.-The olfactory plates of the left olfactory organ in a turbot (Rhombus maximus). The dotted circles show the position of the nostrils, and the arrows the course of the current.

FIG. 5.-Diagram of a single olfactory plate in the turbot, showing the mode of attachment to the rachis.

FIG. 6.-Diagram of the pupil of the rough dog-fish (Scyllium canicula). a, by day ; $b$, by night.

Fit. 7.-Pupil of skate (Raia batis). $a$, by day ; $b$, by night.

FiG. 8.-Eye of torpedo. $a$, by day; $b$, by night.

FIG. 9.-Pupil of angel-fish (Rhina squatina). $a$, by day; $b$, by night.

Fic. 10.-Pupil of sterlet (Acipenser). $\quad a$, by day; $b$, by night.

FIG. 10A.-Pupil of turbot (Rhombus maximus). $a$, by day; $b$, by night.

FIG. 11.-Longitudinal section of skin of barbel of rockling (Motella tricirrata), preserved with gold chloride to show the nerve-fibres traversing the skin to supply the "tastebuds." Zeiss' obj. D, oc. 2.

FIG. 12.-Horizontal section of skin of barbel of rockling (Motella tricirrata), to show the immense numbers of "taste-buds" which it contains. Zeiss' obj. A, oc. 2.

FIG. 13.-Vertical section of skin of lip of conger, showing a "taste-bud," and the nerve running to it in a channel through the skin. Zeiss' obj. D, oc. 2.

FiG. 14.-Vertical section of skin of pharynx of mullet (Mugil), showing a row of "tastebuds." Zeiss' obj. D, oc. 2.

FiG. 15.-Cells of one of the "taste-buds" of a mullet (Mugit) macerated in Hertwig's fluid. Zeiss' obj. F, oc. 2.

FIG. 16.-Cells of "taste-bud" of pollack (Gadus pollachius). Zeiss' obj. D, oc. 2.

FrG. 17.- "Taste-bud" in skin of the tongue of an eel (Anguilla vulgaris), preserved with gold chloride to show the nerve-fibres. 'Zeiss' obj. D, oc. 2. 


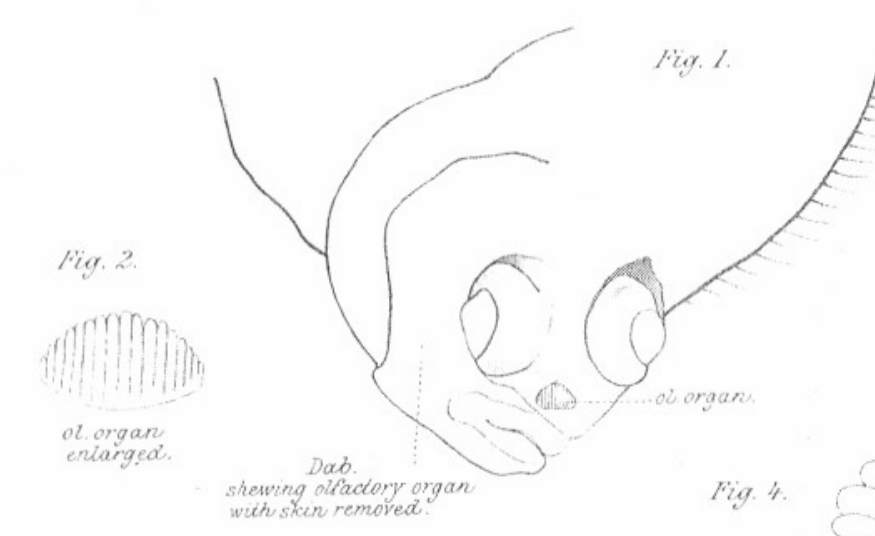
lig. Il sense-organs
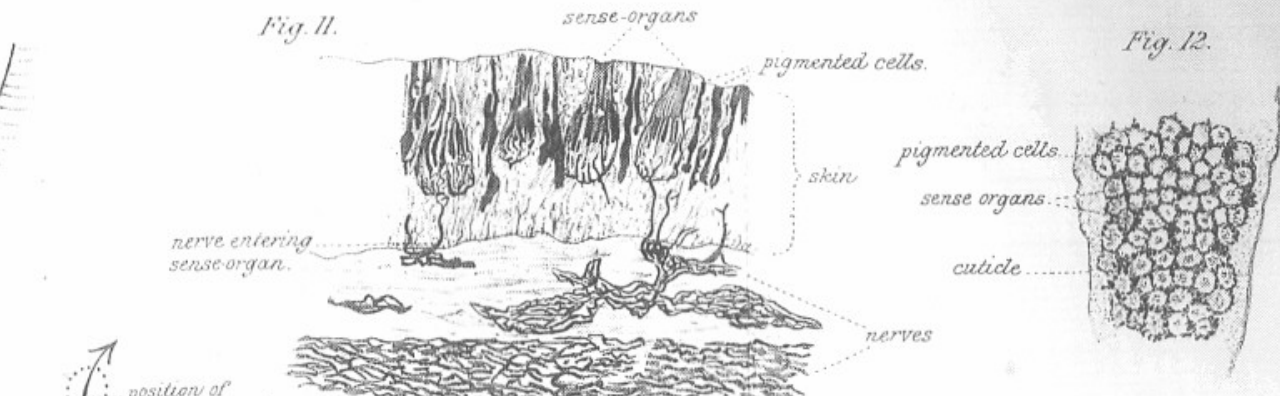

1 position of 1 postion

Fig. 15.
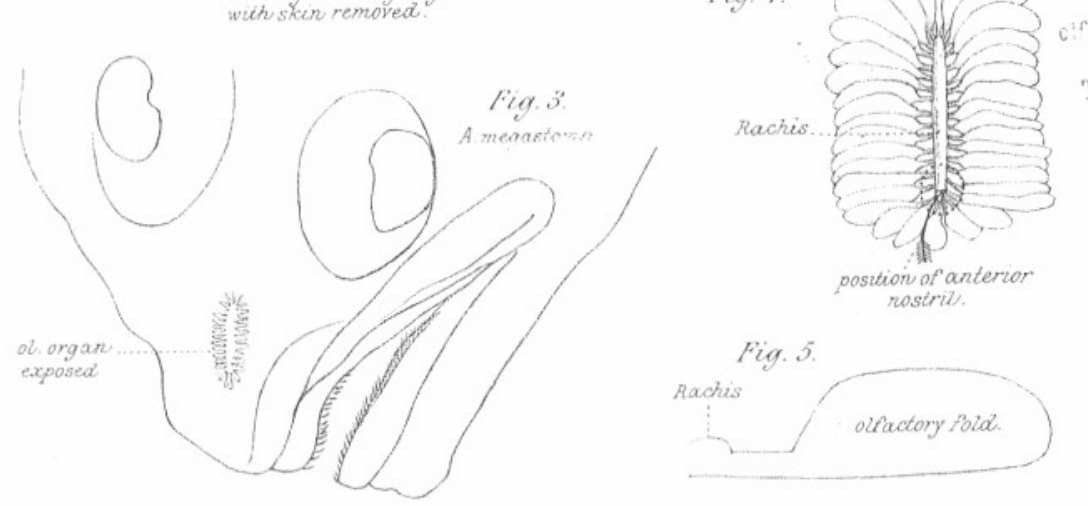

ciractory organ
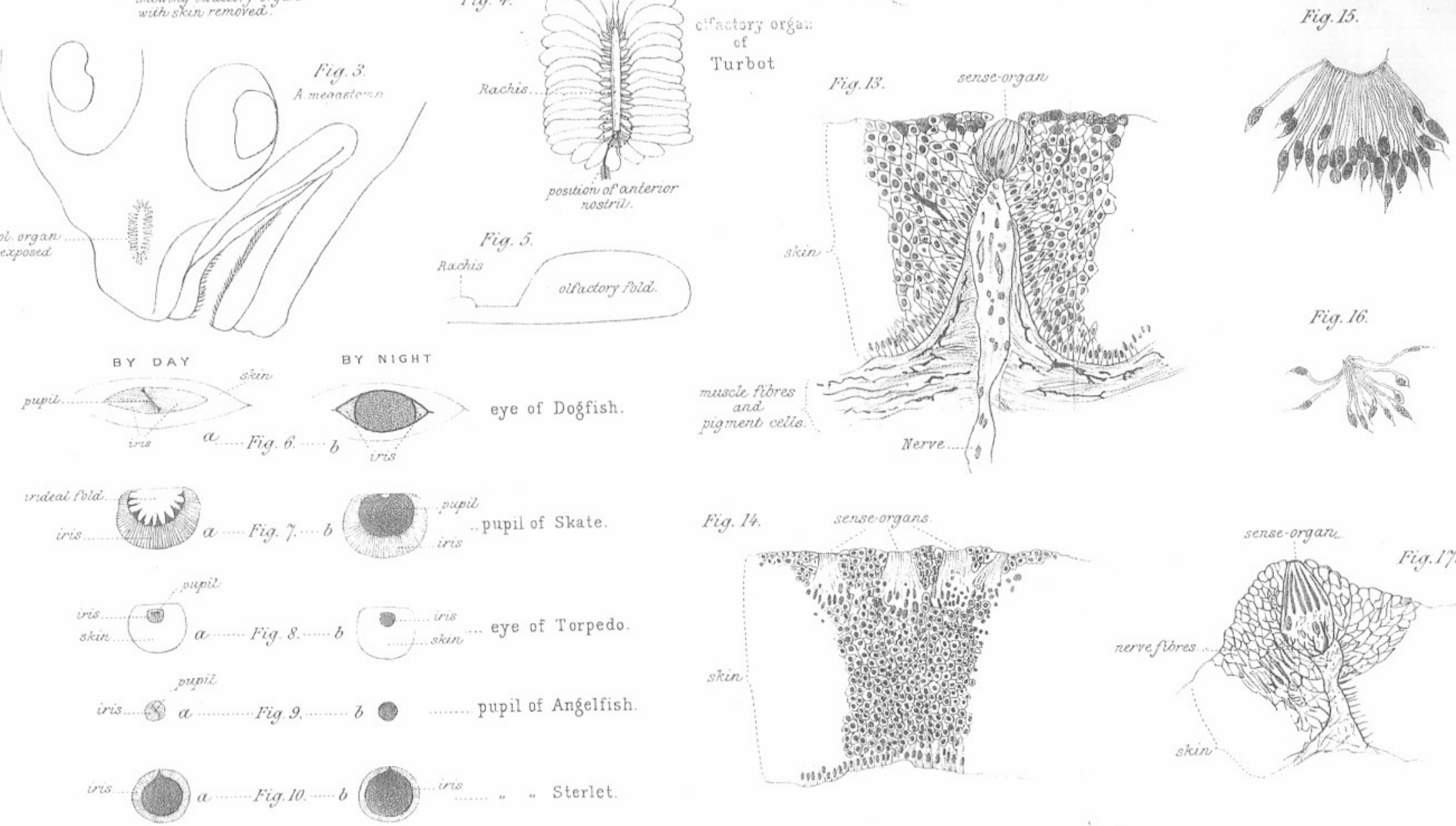

Fig. 14. sense-organs
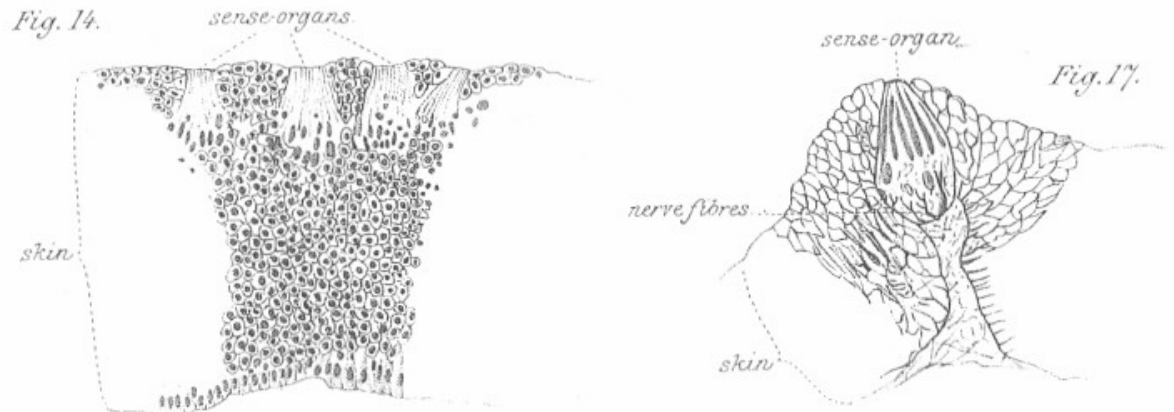